\title{
Orbicularis Oculi Muscle
}

National Cancer Institute

\section{Source}

National Cancer Institute. Orbicularis Oculi Muscle. NCI Thesaurus. Code C52886.

A ring-like band of skeletal muscle on the palpebrae, temple, cheeks, and surrounding the orbit, which originates on the frontal bone, medial palpebral lig ament, and lacrimal bone with insertion on the lateral palpebral raphe, that functions to close the eyelid. 